\title{
Former Footballers in Senegal: Health Condition and Vocational Retraining
}

\author{
Oussseynou Ka ${ }^{1,2, *}$, Oumar Diop ${ }^{2}$, Abdoul Aziz Ndiaye ${ }^{1}$, Ndeye Fatou Ngom ${ }^{1}$, Awa Gaye ${ }^{1}$, \\ Mountaga Elimane Dia ${ }^{1}$, ALioune Badara Tall ${ }^{1}$, Cheikh Tacko Diop ${ }^{1}$, Martial Coly Bop ${ }^{1}$, \\ Boubacar Gueye ${ }^{1}$, Papa Gallo Sow ${ }^{1}$, Abdoulaye Ba $^{3}$, Lamine Gueye ${ }^{1}$ \\ ${ }^{1}$ Department of Community Health of the Sustainable Health and Development Training and Research Unit of Alioune Diop, University of \\ Bambey, Bambey, Sénégal \\ ${ }^{2}$ Center of Gerontology and Geriatrics of Ouakam, Dakar, Sénégal \\ ${ }^{3}$ Department of Physiology of Faculty Medicine, Pharmacy and Odontology of Cheikh Anta Diop University of Dakar, Dakar, Sénégal
}

Email address:

ousseynou.ka@uadb.edu (O.ka)

${ }^{*}$ Corresponding author

\section{To cite this article:}

Oussseynou Ka, Oumar Diop, Abdoul Aziz Ndiaye, Ndeye Fatou Ngom, Awa Gaye, Mountaga Elimane Dia, ALioune Badara Tall, Cheikh Tacko Diop, Martial Coly Bop, Boubacar Gueye, Papa Gallo Sow, Abdoulaye Ba, Lamine Gueye. Former Footballers in Senegal: Health Condition and Vocational Retraining. European Journal of Preventive Medicine. Vol. 7, No. 4, 2019, pp. 71-78.

doi: 10.11648/j.ejpm.20190704.11

Received: June 1, 2019; Accepted: July 11, 2019; Published: July 31, 2019

\begin{abstract}
The objective of this work was to study among former Senegalese footballers their state of health and their socioeconomic situation, an expression of appreciation of their professional retraining. This was a cross-sectional descriptive study from October 2015 to April 2016. Our population consisted of former footballers who played in the Senegalese national championship in the first division or were expatriates, honoring or not a selection in the national team. The cohort consisted of 100 retired footballers, the average age was 57, the average age of sports retirement at 31.8 years, the average duration of sport at 25 years; $56 \%$ of respondents had at least one risk factor, $28 \%$ reported sports-related conditions, $77 \%$ said they did not have reconversion and / or economic difficulties, but only $18 \%$ actually expressed the wish that their children become footballers. Older age was the main reason for sports retreat (49\%) but $67 \%$ of subjects continued to play sports. However, it was noted that the number of risk factors increased with advancing age and longer sporting life and that lean body mass decreased with both indicators. In addition, subjects who engaged in regular physical activity had fewer risk factors and had more lean body mass. This study confirms the positive impact of sports practice in the prevention of risk factors and recommendations have been made to improve the living conditions of former athletes.
\end{abstract}

Keywords: Former Football Players, Sports Retreat, Professional Retraining, Prevention of Risk Factors, Senegal

\section{Introduction}

Retirement for athletes can be a risky break. Indeed, at the end of their career, top athletes face a triple crisis.

A physical crisis: the relationship to the body is upset. Indeed the competition ended, the usefulness of the body, conceived since adolescence as a tool at the service of the sports performances, is questioned. The body begins to disintegrate and can quickly become bulky for the athlete. Some realize that they are experiencing a form of sports addiction. Others, on the contrary, show a brutal rejection of all physical activity [1-2].

A crisis of identity: stopping the sports career is for many, a source of anxiety, or even depression. Ultra specialized in a particular field, the athlete must start a new life in a world where he has few references. Thus he must face this "unrecognized" world; as a result, the feeling of omnipotence disappears. The athlete feels much more vulnerable, far from his image of "Sunday hero". It is difficult for him to turn the page to the extent that he is constantly referred to his athletic past by others "[1-3]. These ancient stars, once adulated, are today in total anonymity. The situation is such that, making the inventory is a breeze for a former international football 
Senegal [4] "those who were to be taken into consideration are left stranded. Recognition is no longer a Senegalese virtue. One has the impression that Senegal has no memory and does not remember its great men, those who, at a given moment, marked the history of the activity in which they excelled ". The assistant coach of the national football team in 1986 [4] says "I think of the footballers and elite athletes who sacrificed their youth, perhaps even their social promotion to serve the nation and who are, today, rejected, abandoned and without support ".

A financial crisis With the exception of big stars, a professional reconversion is essential for financial reasons. In spite of comfortable remuneration, very few former athletes can afford to stop any professional activity so early [1] Nowadays, football is the most practiced and the most publicized sport in the world. The presence of money in this environment in the form of wages, transfers, advertising or contracts, pushes many young people to enter the profession. Unfortunately, in some countries it is not always a significant source of income to cope with socio-economic difficulties. What makes the assistant coach of the national football team say in 1986 [4] that "many former high level footballers have financial difficulties to take charge, they are in general indifference while they had to carry the national torch very high without asking anything". Yet some were brilliant at school, but stopped studying because of the national team. A former international football [4] offers an example; "I went to the final year, but I could not do the baccalaureate. After the matches of my local team in the African Champions League, I played with the national team. I did not have time to concentrate on studying anymore". Becoming after his professional retired assistant coach from his former local football club, he complains of not occupying the proper place to his rank. He denounces "the niche of manager and football coach is well-paid carrier and unfortunately some nonprofessional people specialize in this area at school or in institutes and come direct us."

In addition to the financial aspect, football is also a means of prevention against chronic diseases. However, disadvantages can result from bad sports practice, resulting in illnesses or trauma.

The aim of this work is to study among former Senegalese footballers their state of health and their socio-economic situation, expression of appreciation of their professional reconversion.

\section{Materials and Methods}

\subsection{Framework and Study Period}

Our study took place in Dakar from October 2015 to April 2016, at the Demba Diop stadium and the Dakar Sacré-Cœur football school, during meetings with the "old glories" of Senegalese football. The former glory denomination refers to the Senegalese footballers who had to wear the national team jersey and who retired from sport; they have organized themselves into an association to which even those who have played only at club level can adhere.

\subsection{Population and Inclusion Criteria}

Our study population consisted of males, blacks and Senegalese nationals. We had former footballers who played in the national team championship and had agreed to participate in the study. There was no age limit.

\subsection{Exclusion Criteria}

Ex-footballers whose survey cards did not provide enough information were excluded.

\subsection{Equipment}

We had the following equipment: an examination table, a stethoscope, an arm blood pressure monitor (Omron, healthcare Co., Ltd., Japan) first calibrated using an aneroid sphygmomanometer (Spengler CE 0459, Lian Scénic, France), a tape measure graduated in centimeters, an impedance meter (Omron BF 511 Medicodel, Belgium), a survey sheet containing a questionnaire and a form for the examination data.

\subsection{Methodology}

Former footballers able to understand at first reading the various sections of the survey responded directly to the questionnaire. The others were accompanied, at their request, by explanations. They all agreed to sign the consent form. For those who answered directly, 5 cards were distributed beforehand as a pretest. The investigation continued after checking the quality of the first answers provided. The survey focused on the marital status, socio-economic conditions of former footballers and their suggestions in order to improve the experience of athletes in general. The details of the questions asked are recorded in the survey sheet. Sometimes we give priority to the older ones. The constants measured were blood pressure (BP) in $\mathrm{mmHg}$, heart rate (HR) in beats / minute, weight in $\mathrm{kg}$, and height in $\mathrm{cm}$; these last two allow to calculate the body mass index (BMI) which is obtained by the weight/ size ratio ${ }^{2}$ in $\mathrm{Kg} /$ $\mathrm{m} 2$. Waist circumference was measured using the tape measure. The measurement is done standing, legs slightly apart at shoulder height. The abdominal region cleared of any garment, belt or accessory, the tape-meter is placed under the last rib, and the measurement is made at the end of an expiration. The impedance meter allowed to obtain the lean mass (MM), the total fat mass (MGT) and the visceral fat mass $(\mathrm{MGV})$ expressed as a percentage $(\%)$.

\subsection{Statistical Analysis}

The data was collected on Excel 2007. Statistical analysis was done using Sigma Stat 3.0 software. Quantitative variables were expressed as Mean \pm Standard Deviation or Standard Error; they were expressed as a percentage when reported to others. Qualitative data were expressed as a percentage and correlations were made using the Pearson 
test. The threshold of significance was set at 0.05 .

\section{Results}

In total, out of 107 completed cards only 100 were exploited.

\subsection{Team Types}

Eighty-six (86) players played in local teams and fourteen (14) in foreign teams. Among them 20 players had joined the national team.

\subsection{Anthropometric Data}

The average age was $57 \pm 9.6$ years ( $36-75$ years) with an overrepresentation in the 55-65 age group (40\%). The mean age of onset of sport retirement was $31.8 \pm 5.8$ years (range $20-44)$ and the average duration of sporting activity was $25.2 \pm 11.6$ years (range $2-51$ ). Other anthropometric data showed a mean weight $(\mathrm{Kg})$ of $74.1 \pm 8.7$ (55-93), a mean height $(\mathrm{cm})$ of $178.4 \pm 6.6(165-191)$, an average BMI of $23.2 \pm 2.7(17.4-28.9)$, an average of the total body fat $(\%)$ of $23.7 \pm 5.6(10.2-32.9)$, an average of the mass lean $(\%)$ of $33.5 \pm 3.1(26.9-41.3)$, an average visceral fat mass of $(\%)$ of $6.3 \pm 3.6(1-16)$ and one round of average size $(\mathrm{cm})$ of 85.9 $\pm 6.7(69-104)$.

\subsection{Modifiable Cardiovascular Risk Factors}

Fifty-six (56) subjects had blood pressure above normal values ( $\geq 140 \mathrm{~mm} \mathrm{Hg}$ and / or $\geq 90 \mathrm{~mm} \mathrm{Hg}$ ). Only 18 were actually followed as hypertensives. Smoking was found in 31 subjects including 18 cases still active, not weaned. However, 7 subjects started to smoke during their sports career. They all smoked cigarettes with an average number of packets-year at $9.11 \pm 1.6(0.75-40.5)$.

There were 12 diabetics followed and their treatment included oral antidiabetic drugs. Two subjects reported dyslipidemia known and treated with statins. The same number of cases was found for hyperuricemia. No cases of obesity ( $\geq 30 \mathrm{~kg} / \mathrm{m} 2$ ) were listed. In contrast, the prevalence of overweight and underweight subjects was $25.4 \%$ and $3.2 \%$, respectively. The waist circumference (TT) $\geq 94 \mathrm{~cm}$ was found in $12.7 \%$ of the cases while $1.6 \%$ had a TT $\geq 102$ $\mathrm{cm}$. According to $\mathrm{WHO}$, in man, waist circumference is normal if it is less than $94 \mathrm{~cm}$; there is overweight if it is between 94 and $102 \mathrm{~cm}$, and there is obesity if it is greater than $102 \mathrm{~cm}$. The distribution of risk factors (FDR) was 3 cumulative FDRs for 3 cases, 2 cumulative FDRs for 13 cases and 1 FDR for 39 cases. No modifiable FDR was found in the remaining 45 subjects.

\subsection{Reported Disorders}

Twenty-eight (28) subjects reported sport-related conditions during their careers, most of which involved joint involvement $(20 \%)$ and fractures (8\%). Non-sport-related conditions include asthma (3 cases), phlebitis (1 case) and sciatica (1 case).
On the other hand, after their career, 90 cases of affections were reported, with often an accumulated attack on the same subject. These conditions are mainly oral (38\%), ocular $(21 \%)$, osteoarticular $(20 \%)$, prostatic $(8 \%)$, respiratory $(7 \%)$, cardiovascular $(6 \%)$.

\subsection{Reasons for Retirement and Post-Career Football Practice}

Reasons for retirement are mainly old age (49\%), family constraints $(17 \%)$, work-related constraints $(13 \%)$, injuries $(11 \%)$, diseases $(5 \%)$.

However after their career, $67 \%$ of the subjects continued to practice the sport and among them $38 \%$ did the sport 2 to 3 times a week. In contrast, $33 \%$ of subjects did not practice sport anymore. Other physical and sporting activities were walking $(18 \%)$, swimming $(7 \%)$, cycling $(3 \%)$, and basketball $(2 \%)$.

\subsection{Social Parameters}

Among the respondents, $41 \%$ worked in the liberal sector and $36 \%$ were employees of the administration, $59 \%$ were owners of their homes, $21 \%$ of tenants and $20 \%$ lived with their children, $91 \%$ were married and monogamy accounted for $68 \%, 70 \%$ said they did not have reconversion difficulties and / or economic but only $18 \%$ had really expressed the wish that their children become footballers. On the other hand, the vast majority (62\%) were ambivalent about this issue so there were not many answers.

The average number of children was $4.5 \pm 2.6(0-12)$, while the average number of former footballers in charge was $7.6 \pm 4.5(1-25)$.

The ideas and suggestions made by former footballers for better handling of their concerns and advice to their cadets are:

a) Have the recognition of the Nation,

b) Have a healthy lifestyle including the practice of physical activity after retirement,

c) Have a job other than the sport practiced,

d) To reconcile sport and studies for young people,

e) Financial support and reconversion of the authorities,

f) Have a medical follow-up and set up a health insurance for former athletes,

g) Have sports facilities at their disposal,

h) Integrate football bodies as coach or coach.

\subsection{Correlations}

Age at the time of the survey and length of sporting retirement were positively and significantly correlated with high blood pressure and number of risk factors. In fact, the older the subject is and the longer his sports retreat, he is more exposed to the occurrence of vascular FDRs. On the other hand, these two indicators are inversely correlated with lean mass. (Table 1)

Post-career physical activity and sport activity was negatively and significantly correlated with high blood pressure, diabetes, overweight, waist circumference, total 
body fat, and number of risk factors. On the other hand, the correlation was positive in relation to lean mass (Table 2).

Table 1. Results of correlative studies on the age of former footballers and the length of retirement.

\begin{tabular}{lll}
\hline & AGE $(\mathbf{r} ; \mathbf{p})$ & Duration of retirement $(\mathbf{r} ; \mathbf{p})$ \\
\hline \multirow{2}{*}{ High blood pressure } & 0,327 & 0,245 \\
Systolic blood pressure & 0,0009 & 0,01 \\
& 0,184 & Not significant \\
Risk factors number & 0,06 & 0,2 \\
Fat mass & 0,266 & 0,04 \\
& 0,007 & $-0,275$ \\
\hline
\end{tabular}

NS: non-significant correlation.

Table 2. Results of the correlative studies in relation to the practice of physical activity and sport after the career.

\begin{tabular}{lll}
\hline Parameters & Football alone (r; p) & Football and other activities (r; p) \\
\hline \multirow{2}{*}{ High blood pressure } & $-0,299$ & $-0,211$ \\
Diabetes & 0,002 & 0,03 \\
& $-0,236$ & NS \\
Overweight & 0,018 & $-0,253$ \\
& $-0,233$ & 0,011 \\
Risk factors number & 0,019 & $-0,346$ \\
& $-0,367$ & 0,0004 \\
Waist circumference & 0,0001 & $-0,3$ \\
& $-0,3$ & 0,01 \\
Large total mass & 0,016 & $-0,354$ \\
Fat mass & $-0,375$ & 0,004 \\
\hline
\end{tabular}

$r=$ correlation coefficient; $p=$ value of $p$ (significance of the test).

\section{Comments and Discussions}

\subsection{Anthropometric Data}

Age: The mean age was $57 \pm 9.6$ years old. The 55-65 age group was the most represented (40\%). In fact at this age, the old practitioners still have a capacity and often a great desire to carry out actions in the associative framework.

Retirement age: Sports retreat occurred at an average age of $31.8 \pm 5.8$ years with an average duration of sports practice at $25.2 \pm 11.6$ years. During this period, the footballer becomes very experienced, has the sense of play, but unfortunately his athleticism diminishes under the weight of age. Since football is a very demanding sport in terms of endurance, strength and speed, the athletic impact forces the athlete to think about retirement.

Body Mass Index (BMI): Almost all subjects (71.4\%) had a normal body mass index (BMI), with an average of $23.2 \pm$ 2.7. No cases of obesity had been identified. These results are similar to studies recently conducted in Senegal by WHO [5]. Our study showed that most subjects continued to pursue sport after retirement, which may explain normal BMI in the majority of cases. However, $25.4 \%$ of the subjects were overweight. Indeed, in the sportsman in activity, the diet is in phase with energy expenditure. But in retirement, this balance is disturbed. And the root cause of obesity and overweight is an energy imbalance between the calories consumed and spent. The former athlete will tend to maintain the same diet, most often high calorie, while the practice of physical activity is reduced. Which could explain this average overweight in our study population. It should be noted that numerous studies have shown that the prevalence rate of overweight and obesity has globally increased [6-7]. Today, the expected benefits of weight loss on co-morbidities are palpable as many studies have reported that sustained weight loss of about $5 \%$ to $10 \%$ contributes to significant health benefits $[8,9,10]$.

Waist circumference: Waist circumference was generally normal with an average of $85.9 \pm 6.7$. The latter is a simple indicator of excess fat in the abdomen in adults. Abdominal obesity is defined with specific values of waist circumference according to ethnicity [11]. Waist circumference is associated, independently of BMI, with the development of metabolic and vascular complications of obesity [9, 12, 13]. There is a relative risk of the incidence of certain conditions according to waist circumference, including some coronary heart disease, high blood pressure, type 2 diabetes [14].

Fat mass and lean mass: The total fat mass was overall high with an average of $23.7 \pm 5.6 \%$. Indirect measures of body fat such as impedancemetry (used in our study), skinfold thickness and waist-to-hip ratio have potential applications in clinical research, although pose problems of precision and accuracy [15]. For lean mass we have an average of $33.5 \pm 3.1 \%$ and $6.3 \pm 3.6 \%$ for the visceral mass. 


\subsection{Modifiable Cardiovascular Risk Factors}

Hypertension: Our study shows that $56 \%$ of the subjects had blood pressure levels above the values considered normal (PAS $\geq 140 \mathrm{mmHg}$ and / or DBP $\geq 90 \mathrm{mmHg}$ ). This result confirms that high blood pressure is a real public health problem. In Dakar, the prevalence of arterial hypertension is estimated at $27.50 \%$ [16]. In the vast majority of cases, arterial hypertension is called "essential", that is to say that no known cause can explain its appearance. The disorder appears most often insidiously. There are, however, several risk factors. The age is the main one of them because the aging is associated with a loss of elasticity of the arteries. Other risk factors are overweight, sedentary lifestyle or diet (excess of salt or insufficient intakes of potassium, heavy consumption of alcohol) which contribute to either increasing the volume of blood circulating in the arteries, or to increasing the rigidity of the arteries by a structural effect or vasoconstrictor. In addition, we noted that in our study population, of the 56 hypertensive subjects, only $18 \mathrm{knew}$ that they were hypertensive and were being followed up. This may be due to a lack of awareness about this pathology, the fact that it evolves insidiously and sometimes lack of resources.

Smoking: Smoking was found in 31 subjects. They all smoked cigarettes with an average number of packets-year estimated at $9.11 \pm 1.6$. The links between intensive sports practice and consumption of psycho-active products, including tobacco, have been the subject of much research for two decades [17]. This interest of the researchers comes from the questioning on the harmful effects of the intensive sport practice suspected to increase the risk of use of these products. However, as is often the case in public health, some studies in adolescents have shown a protective effect of sports activity on the consumption of alcohol, tobacco and illegal drugs. Other studies suggest that the links between sports practice and consumption of psychoactive products depend on the one hand on the type of sport activity, the level of competition and the context of the practice on the one hand and on the other hand the type of psychoactive product. They also indicate that these links depend on sex and age, so that they are relatively complex to analyze [17].

In our study population, most of the smokers started to smoke after retirement. There were 19 out of 31 subjects. Indeed a high level athlete is usually followed day by day by one or more "coaches" (coach, fitness trainer, dietician...), training, competitions and recovery fill his schedule: his sports practice structure almost every aspect of his daily life. Once the career of the athlete ceases, he is then faced with a brutal desocialization, which may expose him to uses of psychoactive substances uncontrolled. This has been observed in two French studies, one quantitative and one qualitative [17-18]. The second also suggests that high-level sportspeople from popular backgrounds are more exposed than those from better-off backgrounds, who have more social resources available when their career ends [18-19]. To a certain extent, it is possible that the more the sport has protected the individual during his career, the more vulnerable he becomes when the sport comes to an end.

In addition, we also noted 7 cases that started smoking during their sports career. Competitions generate anxiety, and drug use may sometimes appear as a remedy to relieve it, which would explain why, among young high-level athletes, those who compete in the most prestigious competitions are more likely to consume tobacco and alcohol [18].

Among the 31 subjects we had 18 cases still active, not weaned, which could be linked to dependency. Indeed, tobacco smoke contains tiny amounts of nicotine that are not deadly by themselves, but that cause dependence on cigarettes, especially because they stimulate the brain in seconds. The smoker thus finds an immediate benefit in relation to what he is looking for, such as the appeasement against a feeling of stress, anxiety, etc. Also it was noted that tobacco would have an impact on the performance of athletes by mainly affecting the respiratory system, cardiovascular system and muscles. However, some smokers do not immediately feel the effects of tobacco on their sports activity: no shortness of breath, no decrease in performance, while their respiratory, cardiovascular and muscular abilities are already objectively diminished [20].

Diabetes: The diabetics followed were 12, they took oral antidiabetic coupled to the diet. These cases of diabetes are frequently associated with other risk factors such as sedentary lifestyle, hypercholesterolemia, overweight or hypertension. All the diabetics identified had at least one risk factor with more or less an impact on the occurrence of diabetes. The disease causes serious long-term complications. It is all the more insidious as it is most often asymptomatic. These complications can occur after several years of glycemic imbalance. They mainly concern the arteries and micro-vessels of the heart, kidneys, peripheral nerves and the retina.

The distribution of modifiable risk factors: We identified 3 subjects cumulating 3 risk factors, 13 subjects cumulating 2 risk factors and finally 39 subjects presenting only one risk factor. In total, there are 55 subjects with at least one risk factor. The more or less important association of these risk factors is part of the Metabolic Syndrome, the definition of which is still highly controversial. Among the many definitions proposed two refer to: the World Health Organization (WHO) [21] and the National Cholesterol Education Program (NCEP ATP III) [22]. However there is a consensus to talk about metabolic syndrome in cases where at least 3 of the following factors are associated in the same person with criteria for each determinant: hyperinsulinism, dyslipidemia, high blood pressure, excess weight, and finally hyperglycemia. [23]

Each of these physical or biological signs is a cardiovascular risk factor in itself. The question is, however, always debated whether the combination of several factors increases the cardiovascular risk beyond their simple addition.

\subsection{Reported Pathologies}

Pathologies reported during sporting career: We had listed 
32 cases that had an affection during their career. Among them, 28 subjects had reported that their pathologies were related to sport. They consist of joint lesions ( 20 cases) and fractures ( 8 cases). Studies show that ball sports, especially football, top the list when it comes to injuries. The BPA (Office of Accident Prevention) in Switzerland counts, from 2000 to 2004, for the age group 16-65, 52900 cases of injuries related to the practice of football, far ahead of sports such as volleyball (8700 cases) or basketball (6300 cases). These same statistical tables show that young people aged 26 to 45 represent the age group most at risk of injury during their sporting activities. These figures can be explained in particular by the fact that this age group has the highest number of practitioners [24].

\subsection{Reasons for Retirement and Post-Career Sport}

Reasons for Retirement: Older age was mentioned by almost half of our study population $(49 \%)$ as the primary reason for sport retreat. It is a valid reason, especially since we know that at an advanced age the physical capacities regress because of the weakening of the physiological functions. For some, this retreat occurred early due to further study. Just under a third of respondents (31\%) justify their retirement by socio-professional constraints resulting either from a difficulty in managing workloads in relation to the demands of high level sport, or from the non-satisfaction of the income generated by football. compared to other professions. In contrast, $16 \%$ of subjects linked sport retirement to an illness or injury contracted. However, whether you are a professional, high-level or simply an amateur footballer, the injury and / or the illness remain one of the main fears of all athletes. It is obvious that depending on the severity, the consequences will not be the same. They can be very disabling, or even stop the sporting career. Only one case had mentioned the absence of a club as a reason for retirement. We also noted a case of complacency, which is said to have won everything in football, and can be explained by a "self-esteem".

Post-career sport practice: Almost two-thirds of former athletes $(67 \%)$ continued to play football at least once a week. This shows the practitioner's attachment to his sport. Some athletes may develop an addiction to sport during their career and this tends to persist even after retirement. An author like D. VEALE has worked hard on this notion to the point of setting up the criteria of dependence on sport [25]. Indeed, sport leads to release of endorphins, a source of physical well-being. Their biochemical similarity with products such as morphine, trigger the desire to constantly seek this pleasant sensation, up to a compulsive tendency. People who play sports additively, could do this to increase their self-esteem. They can also arrive at this addiction because they fill an emotional emptiness by the sporting practice [25]. Other former athletes have returned to other sports or physical activities with or without football. First, we find walking (18\%), swimming ( $7 \%$, coupled with tennis in 1 case), cycling (3\%), and basketball $(2 \%)$. Apart from the fact that there may be a notion of addiction to sport, some sportsmen often want to discover other disciplines after lifting the constraint related to the one they practiced. They can continue to pursue physical activity after their career to seek physical well-being. For others, physical activity can be a way to break the isolation that occupational retirement and advancing age are gradually leading [6].

\subsection{Social Parameters}

Regarding marital status, 91\% of former athletes are married. This situation reflects African societies. Establishing a home gives a certain status, embodies respect and a sense of responsibility. We also noted that $68 \%$ of married couples are monogamous, which can be explained by the difficult living conditions. Being polygamous requires a lot more money. The average number of children per athlete was $4.5 \pm$ 2.5 , as is the African society where families are numerous, in relation to our socio-cultural context where the population is mainly young and the family is larger. The average number of people whose former footballers were in charge was $7.6 \pm$ 4.5, which is not negligible. In Africa it is difficult to live in a nuclear family. This situation can help build links and strengthen family cohesion, but can exacerbate socioeconomic difficulties. Most of the former athletes (77\%) are still active economically. These elders work in the liberal sector (41\%), or are employees of the Senegalese administration (36\%). We noted that $23 \%$ of our study population had reconversion and / or socio-economic difficulties and only $18 \%$ wanted their children to become footballers. This not insignificant percentage shows that football in Senegal did not allow to have a certain financial autonomy. Therefore we should be a little more interested in the advent of so-called professional football in Senegal created in 2009, to see if the socio-economic situation of the footballer has improved or not. Former footballers have put forward suggestions that boil down to advocacy. They want a lot more recognition from the nation. They would also like the authorities to put in place structures enabling them at best to prepare for sports retreat and reconversion. They also gave advice to the younger generation by encouraging them to always combine sports and education. They invite their fellow former athletes to continue regular physical activity, coupled with a healthy lifestyle.

\subsection{Correlations}

Age and length of retirement: Our study shows that the older the age, and the longer the duration of the retirement, the greater the number of risk factors, including high blood pressure. Since age is a non-modifiable risk factor, it is not surprising that it is positively correlated with the occurrence of hypertension and the number of risk factors. The length of retirement can be an additional factor especially for those who have become sedentary. Lean mass was negatively correlated with age and length of retirement. The more they increased, the leaner mass was important. This is related to sarcopenia, which represents a progressive and ineluctable loss of age-related muscle mass. 
Physical activity and sports after the career: Our results show that the practice of physical activity and sports was negatively and significantly correlated with hypertension, diabetes, overweight, waist circumference, total body fat and the number of risk factors. In contrast, the correlation was positive compared to lean mass. These reflect the importance of physical activity in the primary prevention of risk factors. Sport has become a factor of balance of the body. In this context, we practice sport to maintain, to age less. We know that the practice of physical activities from the age of 60 maintains a good functional level despite the age and can promote the improvement of certain respiratory, cardiac, muscular and articular abilities.

\section{Conclusion}

Football was known to be a recreational sport first and foremost. At present, it is considered as a profession in its own right. Nowadays, it is the most practiced sport and the most publicized in the world. The fact that we live in a capitalist society reinforces the presence of money in the football world. The financial and media aspect that it encourages, pushes footballers to try to outdo themselves and makes the decision of a retirement difficult. When putting an end to a career, the top athlete must face a physical crisis, an identity crisis and a financial crisis. Thus the athlete must be prepared before retirement for the reality of life that was "unknown" to him.

Football is also a physical activity. It has many virtues and is an excellent way to guard against chronic diseases. The benefits can therefore be obtained, both by the competitive practice, and by the practice of leisure. However, it would be absurd to deny that there are also potential risks associated with the practice of this sport.

Thus, the following recommendations were made:

With the advent of professional football in Senegal; all sportsmen and women should organize themselves into a football trade union and establish a social security fund that would allow them to better organize their careers and facilitate their professional integration after retirement.

Ministries in charge of education, higher education, sports, and the public service should work closely together to put in place not only projects that allow athletes to combine their profession with studies but also for former athletes to benefit from income generating projects.

Promote the practice of regular and rational physical activity in the elderly, in the prevention of chronic diseases.

Make all sports fans aware of the possible risks linked to high performance sport, although rare, keeping in mind that its benefits are much more numerous.

\section{Conflict of Interest}

All the authors do not have any possible conflicts of interest.

\section{Acknowledgements}

We thank our dear teacher Pr Lamine Gueye, Rector Alioune Diop, University of Bambey, the research team "Health and Nnutrition" of Alioune Diop University and the research team "Health and Transitions in Africa" of the Unit Mixed International 3189 Environment, Health, Societies.

\section{References}

[1] Scottish Intercollegiate Guidelines Network. Management of obesity. A national clinical guideline. Edinburgh: SIGN; 2010. http://www.sign.ac.uk/pdf/sign115.pdf.

[2] Tuomilehto H, Gylling H, Peltonen M, Martikainen, et al. Sustained improvement in mild obstructive sleep apnea after a diet- and physical activity-based lifestyle intervention: post interventional follow-up. Am J Clin Nutr 2010; 92 (4): 68896.

[3] Prothoy I. Epidémiologie des traumatismes en football. [En ligne]. http://asesg79.fr/index.php/sante/traumatismes-enfootball. [03/07/2016].

[4] Situation des anciens internationaux de la grandeur a la décadence Leral.net Rédigé par leral.net le Mercredi 23 Mai 2012 à 16:56 | http://www.leral.net/Situation-des-anciensinternationaux-de-la-grandeur-a-la-decadencea40281.html.

[5] OMS, Aide-mémoire N³39, «Tabagisme». Juillet 2015. [En ligne]. http://www.who.int/mediacentre/factsheets/fs339/fr/, [27/06/16].

[6] Institut de recherche de Taïwan, «15 minutes par jour pour gagner trois ans de vie», Lancet 2011. http://www.lefigaro.fr/flash-actu/2011/08/16/9700120110816FILWWW00225-du-sport-pour-vivre-pluslongtempsetude.php.

[7] Institut national de la santé et de la recherche médicale. Obésité. Bilan et évaluation des programmes de prévention et de prise en charge. Paris: Inserm; 2006. http://www.inserm.fr/thematiques/santepublique/expertisescollectives.

[8] Filloux S. et al. «Sport et tabac: parlons-en!». Fare S, Bruxelle, décembre 2010, 26 pages.

[9] Institut de veille sanitaire. Étude nationale nutrition santé ENNS, 2006.Situation nutritionnelle en France en 2006 selon les indicateurs d'objectif et les repères du Programme national nutrition santé (PNNS). Saint-Maurice: Invs; 2007. http://www.invs.sante.fr/publications/2007/nutrition_enns/RA PP_INST_ENNS_Web.pdf.

[10] Rechik V. Lindsay M. Nowak A. Sport et santé, «les blessures chez les sportifs». [Document électronique]. Genève, Immersion, 2007, http://www.medecine.unige.ch/enseignement/apprentissage/m odule4/immersion/archives/2006_2007/trav aux/07_r_sport.pdf.

[11] Ined. Le Vieillissement normal: Données épidémiologiques et sociologiques. [Document électronique]. France, 2007, http://www.medecine.upstlse.fr/dcem3/module05/54_poly_viellissement_2.pdf. p30. 
[12] Institut national de la santé et de la recherche médicale, TNS Heath care Sofres, Roche. Enquête épidémiologique nationale sur le surpoids et l'obésité. Obépi 2009. Neuilly-sur-Seine: Roche; 2009.

http://www.roche.fr/gear/newcontents/servlet/stati c files Servlet? type=data\&community $\mathrm{Id}=$ re $71901 \& \mathrm{id}=$ static /attached file/ re7300002/ re72700003 / Atta chedFile_10160.pdf.

[13] World Cancer Research Fund, American Institute for Cancer Research. Food, nutrition, physical activity and the prevention of cancer: a global perspective. London: WCRF; 2007. http://www.dietandcancerreport.org/.

[14] National Collaborating Centre for Women's and Children's Health. Fertility assessment and treatment for people with fertility problems. London: NCCWCH; 2004. http://www.nice.org.uk/nicemedia/live/10936/2926 9/29269.pdf.

[15] National Heart, Lung, and Blood Institute. Clinical guidelines on the identification, evaluation, and treatment of overweight and obesity in adults. Bethesda: NIH; 1998. http://www.nhlbi.nih.gov/guidelines/obesity/ob_gdl ns.pdf.

[16] Marcia E., Duboz P., Gueye L. «L'hypertension artérielle à Dakar: prévalence, connaissance, traitement et contrôle», Bulletin de la Société de pathologie exotique. 108, Issue1 (2015), p49-56.

[17] Verger P. «Sport intensif ou de haut niveau, quelles consommations d'alcool et de tabac?», performance et santé. 16 pages, $\mathrm{n}^{\circ} 16$ (Décembre 2012), p3.

[18] Leroux M. Consommations intégrées et sport de haut niveau, dans Société avec drogue. Enjeux et limites. (sous la direction de C. Faugeron et M. Kokoreff), Editions Erès, 2002: 79-97); Leroux M. 2002. Consommations intégrées et sport de haut niveau, dans Société avec drogue. Enjeux et limites. (sous la direction de C. Faugeron et M. Kokoreff), Editions Erès, 2002: 79-97.

[19] Lenz M, Richter T, Mühlhauser I. The morbidity and mortality associated with overweight and obesity in adulthood. A systematic review. Dtsch ArzteblInt 2009; 106 (40): 641-8.

[20] Fergusonn F J., Cote P., Gauthier P., et coll. Physical training and myocardial substrate metabolism at rest and exercise in coronary artery disease patients. Circulation. 1976, 54, (Abstr. 0572): II-147.

[21] Alberti KGMM, Zimmet P Z. For the WHO Consultation. Definition, diagnosis and classification of diabetes mellitus and its complications. Part I. Diagnosis and classification of diabetes mellitus. Provisional report of a WHO consultation. Diabet Med 1998; 15: 539-53.

[22] European Association for the Study of Obesity, Tsigos C, Hainer V, Basdev ant A, Finer N, Fried M, et al. Management of obesity in adults: european clinical practice guidelines. Obes Facts 2008; 1 (2): 106-16.

[23] The Swedish Council on Technology Assessment in Health Care. Obesity: problems and Interventions. A systematic review. Summary and conclusions. Stockholm: SBU; 2002. http://www.sbu.se/upload/Publikationer/Content0/ 1/obesity_2002/obsesityslut.pdf.

[24] Lenz M, Richter T, Mühlhauser I. The morbidity and mortality associated with overweight and obesity in adulthood. A systematic review. Dtsch Arzteb IInt 2009; 106 (40): 641.

[25] Entrainement de foot. Addiction au football. [en ligne]. http://entrainementdefoot.fr/addiction-au-football/ [03/07/2016]. 